\title{
Comparison of cyclic fatigue resistance and shaping ability between two single-file reciprocating systems in curved canals
}

\author{
Ezgi Doğanay Yıldız, ${ }^{1}$ Hakan Arslan, ${ }^{2}$ Meltem Sümbüllü,, ${ }^{2}$ Mine Büker, ${ }^{2}$ \\ İbrahim Şevki Bayrakdar, ${ }^{3}$ Ertuğrul Karataş, ${ }^{2}$ Muhammet Akif Sümbüllü̈ \\ ${ }^{1}$ Department of Endodontics, Kırıkkale University, Faculty of Dentistry, Kırıkkale, Turkey \\ 2Department of Endodontics, Atatürk University Faculty of Dentistry, Erzurum, Turkey \\ ${ }^{3}$ Department of Oral Diagnosis and Radiology, Osmangazi University Faculty of Dentistry, Eskişehir, Turkey \\ ${ }^{4}$ Department of Oral Diagnosis and Radiology, Atatürk University Faculty of Dentistry, Erzurum, Turkey
}

\begin{abstract}
Objective: To evaluate cyclic fatigue resistance in simulated canals as well as transportation, centering ability, and preparation time of two single-file reciprocating systems in curved canals of mandibular molars.
\end{abstract}

Methods: Reciproc and NIC instruments (size 25) were tested in steel canals with $3 \mathrm{~mm}$ radius and $60^{\circ}$ angle of curvature $(n=20)$. The time to fracture was recorded in seconds. For the second part , 20 mesial root canals of mandibular first molars with curvature angles of $35^{\circ}-70^{\circ}$ and radii of 2-6 mm were instrumented using NIC and Reciproc instruments. Cone-beam computed tomography scanning was performed both pre- and post-instrumentation. Root canal transportation and the centering ratio were calculated, and the data were analyzed using independent sample t test $(p=.05)$.

Results: No significant differences were found between Reciproc and NIC instruments in terms of cyclic fatigue ( $p>.05$ ). At 3, 5, and $7 \mathrm{~mm}$ levels, there was no significant difference in the root canal transportation and centering ratio between the groups ( $p>.05)$.

Conclusion: Within the limitations of this study, cyclic fatigue values the root canal transportation and centering ratio of the NIC was similar to that produced with the Reciproc.

Keywords: Centering ability; cyclic fatigue; reciprocation; root canal instrumentation; transportation.

Manufacturing and marketing nickel-titanium ( $\mathrm{NiTi})$ rotary instruments became feasible in the early 1990s. Despite their advantages, NiTi instruments may fracture inside the root canal without any sign. ${ }^{[1]}$ Cyclic fatigue and torsional fatigue are the main mechanisms of the fracture of NiTi instruments. $^{[2]}$ Torsional failure occurs when part of the instrument binds to the dentin. ${ }^{[3]}$ Cyclic fatigue fracture of the instrument occurs when the instrument rotates freely in a curvature, generating tension/compression cycles in the region of the maximum şexure until fracture occurs. ${ }^{[1]}$

Root canal transportation is another issue and can occur as a result of root canal instrumentation in curved root canals. ${ }^{[4]}$ Inside the curved root canal, the instrument has a tendency to recover its original shape.$^{[5]}$ Several studies demonstrated that flexible NiTi instruments resulted in a more centered root canal instrumentation than nonflex-

Correspondence: Dr. Ezgi Doğanay Yıldız. Kırıkkale Diş hekimliği Fakültesi,

Endodonti Anabilim Dalı, Kırıkkale, Turkey.

Tel: +90 318 - 2244927 e-mail: dtezgidoganay@gmail.com

Submitted: February 25, 2017 Accepted: June 12, 2017 
ible stainless steel hand files. ${ }^{[6,7]}$

Technological advancements in NiTi instruments have led to new concepts for its use, different kinematics, and improved alloy that increase the cyclic fatigue resistance of the instruments. Reciproc (VDW, Munich, Germany) is a NiTi single-file system made from M-Wire technology. It was designed for usage in reciprocating motion. The life span of instruments and their resistance to fatigue is extended by this motion compared with that by continuous rotation movement. ${ }^{\left[{ }^{8-10]}\right.}$ Recently, a new NiTi instrument, NIC reciprocating instrument (Shenzhen Superline Technology Co., Ltd; Guangdong, China) was manufactured for use in reciprocating motion. It was designed for cutting in counter-clock wise direction like Reciproc instruments. To the best our knowledge, no data are available on the cyclic fatigue and root canal transportation study comparing NIC and Reciproc instruments. Therefore, this study aimed to evaluate the cyclic fatigue resistance in simulated canals as well as transportation, centering ability, and preparation time of two single-file reciprocating systems in curved canals of mandibular molars by means of cone-beam computed tomography (CBCT). The null hypothesis was that there would be no significant difference between the groups in terms of (1) cyclic fatigue and (2) root canal transportation (3) centering ability, and (4) preparation time.

\section{Materials and methods Cyclic fatigue}

The cyclic fatigue of Reciproc R25 (VDW, Munich, Germany) and NIC size 25 reciprocating instruments (Shenzhen Superline Techology Co., Ltd; Guangdong, China) were tested $(n=20)$. Each instrument was inspected for defects or deformities before the experimental procedures under a stereomicroscope (Novex, Arnhem, Holland). No defective instrument was found.

An apparatus was used for the cyclic fatigue testing as that used in Larsen, Watanabe. ${ }^{[11]}$ An artificial canal was made out of a testing block of stainless steel with an inner diameter of $1.5 \mathrm{~mm}$, a $60^{\circ}$ angle of curvature, and a curvature radius of $3 \mathrm{~mm}$. The working length was standardized to $19 \mathrm{~mm}$ for all the instruments. The canals were covered with glass to prevent the instruments from slipping out. To reduce the friction of the file as it contacts the artificial canal walls, lubricant oil (KaVo Spray; KaVo Dental $\mathrm{GmbH}$, Biberach, Germany) was used for lubrication. For all groups, the instruments were operated using an electric motor (Satelec Endo Dual, Acteon, France) that enables the user to modify and set the reciprocating angles in both $\mathrm{CW}$ and $\mathrm{CCW}$ directions. The angle of reciprocation was set to $\mathrm{CCW}=150^{\circ}$ and $\mathrm{CW}=30^{\circ}$ (angle of progression for each reciprocation was $120^{\circ}$ ) at $300 \mathrm{rpm}$ for instrumentation.

The instruments were used until fracture occurred. The time to fracture was recorded in seconds. After the instrument was positioned in the artificial canal, the motor was started and timing was initiated. As soon as the instrument breakage occurred, the timing was stopped.

\section{Transportation, centering ability, and preparation time}

Mandibular first molars were selected from a collection of teeth that had been extracted for reasons unrelated to this study. The teeth were stored in distilled water until use. The initial inclusion criterion was a tooth having visible curvature in the mesial root. The teeth were decoronated, and the distal root was separated. Next, the teeth were fixed in a silicone impression material and numbered. The mesial roots were scanned with a CBCT scanner (NewTom FP QR-DVT 9000 Verona, Italy), and the images obtained were analyzed using image analyzing software (ImageJ; http://imagej.nih.gov/ij/) to determine the curvature and the radius. Straight lines, with the same lengths, beginning from the apical and coronal regions were drawn. The midpoints of the lines were marked, and a circle was drawn over the midpoints. The radii were measured, and the angle between the lines was recorded as the curvature angle.

Roots with curvature angles of $35^{\circ}-70^{\circ}$ and radii of 2-6 $\mathrm{mm}$ were included in the study. According to these criteria, 20 specimens were selected for the study and assigned according to the curvature and radius to two root canal shaping procedures $(\mathrm{n}=10)$. One-way ANOVA revealed that there was no significant between-group difference in the canal curvatures and radii $(p>05)$.

The working length of the canals was determined by inserting a \#10 K-file (Dentsply Maillefer) into the root canal terminus and subtracting $1 \mathrm{~mm}$ from this measurement. Each instrument was used in one root canal. Root canal instrumentation was performed using either Reciproc R25 (VDW) or NIC size 25 reciprocating instruments (Shenzhen Superline Techology Co., Ltd). The preparation times for the groups were also recorded.

After completion of the root canal instrumentation, the roots were placed in a silicone impression material using the same setup as that used in the preinstrumentation. Scanning was performed with images obtained at 3,5 , and $7 \mathrm{~mm}$ from the apical terminus of the root for both preand post-instrumentation. Root canal transportation was calculated for each level using the following formula, as described by Gambill, Alder: ${ }^{[12]}\left(\mathrm{x}_{1}-\mathrm{x}_{2}\right)-\left(\mathrm{y}_{1}-\mathrm{y}_{2}\right) \cdot \mathrm{x}_{1}$ and $\mathrm{x}_{2}$ represent the shortest mesial distances from the outside 
of the curved root to the periphery of the uninstrumented and instrumented canal, respectively; $\mathrm{y}_{1}$ and $\mathrm{y}_{2}$ represent the shortest distal distances from the outside of the curved root to the periphery of the uninstrumented and instrumented canal, respectively. The canal centering ratio at each level was calculated using the following formula: ${ }^{[12]}$ $\left(\mathrm{x}_{1}-\mathrm{x}_{2}\right) /\left(\mathrm{y}_{1}-\mathrm{y}_{2}\right)$ or $\left(\mathrm{y}_{1}-\mathrm{y}_{2}\right) /\left(\mathrm{x}_{1}-\mathrm{x}_{2}\right)$.

\section{Statistical analysis}

Data were analyzed using independent sample $t$ test $(\mathrm{p}=.05)$. Because there was only one comparison, the level of significance used was $\mathrm{p}<.05$ without Bonferroni adjustment. The statistical analyses were performed using IBM $^{\circledR}$ SPSS $^{\circledast}$ Statistics 20 software (IBM SPSS Inc., Chicago, USA) at the $95 \%$ confidence level $(\mathrm{p}=.05)$.

\section{Results}

\section{Cyclic fatigue}

The mean time to fracture was $1,087.6 \pm 91.92 \mathrm{~s}$ for Reciproc group and $1,080.6 \pm 52.69 \mathrm{~s}$ for NIC group. No significant differences were found between Reciproc and NIC instruments in terms of cyclic fatigue ( $\mathrm{p}>.05)$ (Table 1$)$.

\section{Transportation, centering ability, and preparation time}

Table 2 shows the root canal transportation and centering ratio values at the 3,5 , and $7 \mathrm{~mm}$ levels for the groups. At these three levels, there was no significant difference in the root canal transportation and centering ratio between the groups ( $p>.05)$. No instrument fracture occurred during instrumentation in any of the groups. The mean and standard deviation for the preparation time were $1.05 \pm 0.43$ minutes for Reciproc and $1.16 \pm 0.71$ minutes for NIC.
There were no significant differences in the preparation time between the Reciproc and NIC groups $(\mathrm{p}<.05)$.

\section{Discussion}

CBCT is a noninvasive and reliable method for evaluating root canal geometry. ${ }^{[13]}$ Previous studies confirmed that $\mathrm{CBCT}$ was useful to assess the effectiveness of rotary systems with regard to root canal geometry. ${ }^{[14,15]}$

According to the results, the null hypothesis was accepted because no statistically significant differences were found between the groups in terms of cyclic fatigue, root canal transportation, centering ability, and preparation time $(p>.05)$. There is no information in the available literature on cyclic fatigue and root canal transportation concerning the comparison of a NIC and other instruments. To our knowledge, no study has compared these instruments. Therefore, further investigations with similar experimental set-ups should be performed to reassess the results.

Kiefner, $\operatorname{Ban}^{[10]}$ compared the cyclic fatigue resistance of two geometrically similar NiTi instruments used in conditions similar to clinical use in reciprocating and continuous rotary motion. They used a simulated canal in a steel block with $1.4 \mathrm{~mm}$ diameter, $60^{\circ}$ angle of curvature, and $5 \mathrm{~mm}$ curvature radius. According to the results, time to fracture of Reciproc 25 instrument was found to be $2066.4 \mathrm{~s}$. In the present study, the mean time to fracture was 1087.6 $691.92 \mathrm{~s}$ for Reciproc group. This difference may be because of various reasons, the most likely reason being using different diameter and curvature radius in simulated canal.

To evaluate the cyclic fatigue resistance of $\mathrm{NiTi}$ instruments, different methods have been described. ${ }^{[11,16]}$ In many reports, a simulated canal in a steel block was used to evaluate the cyclic fatigue of NiTi instruments.

Table 1. The mean time to fracture and fragment length for the groups. There was no statistically significant differences between the groups in terms of mean time to fracture $(p>05)$

\begin{tabular}{lccccc} 
Brand & $\mathbf{n}$ & $\begin{array}{c}\text { Mean time to } \\
\text { fracture (s) }\end{array}$ & $\begin{array}{c}\text { Standard } \\
\text { deviation }\end{array}$ & $\begin{array}{c}\text { Fragment } \\
\text { length }(\mathbf{m m})\end{array}$ & $\begin{array}{c}\text { Standard } \\
\text { deviation }\end{array}$ \\
\hline Reciproc & 20 & 1087.6 & 91.9 & 15.1 & 0.68 \\
NIC & 20 & 1080.6 & 52.6 & 15.06 & 0.08 \\
\hline
\end{tabular}

Table 2. Mean Root Canal Transportation ( $\mathrm{mm}$ ) and Centering Ratio Values of the Tested Groups. There were no significant differences between the groups in the transportation and canal centering values at any level ( $p>0.05)$

\begin{tabular}{lcccc} 
Group & Variable & $\mathbf{3} \mathbf{~ m m}$ & $\mathbf{5 ~} \mathbf{~ m}$ & $\mathbf{7 ~} \mathbf{m m}$ \\
NIC & Transportation & $0.110 \pm 0.128$ & $0.110 \pm 0.128$ & $0.100 \pm 0.105$ \\
\multirow{3}{*}{ Reciproc } & Centering ratio & $0.000 \pm 0.000$ & $0.041 \pm 0.131$ & $0.143 \pm 0.198$ \\
& Transportation & $0.050 \pm 0.108$ & $0.100 \pm 0.105$ & $0.130 \pm 0.133$ \\
& Centering ratio & $0.214 \pm 0.304$ & $0.173 \pm 0.213$ & $0.116 \pm 0.211$ \\
\hline
\end{tabular}


${ }^{[17-19]}$ Similarly, in the present study a simulated canal in a steel block was used for the cyclic fatigue testing. Plotino, Grande ${ }^{[20]}$ reported that the convex cylinder contacts the tapered instrument in a nonpredictable way so that the instrument may fit loosely and radius and angle of curvature may not be repeatable. As a result, it is difficult to control exactly the depth of the instrument in these devices so that the point of the instrument, which lies in the center of the curvature, may vary consistently. ${ }^{[10]}$ Therefore, the experimental design using simulated canal in a steel block could not simulate the clinical conditions. Despite the disadvantage of this experimental design, according to the results of the present study the fragment length was approximately $15 \mathrm{~mm}$ for both brands of instruments.

In the present study cyclic fatigue and root canal transportation were evaluated for NIC and Reciproc instruments. The NIC instruments have similar cyclic fatigue values to Reciproc instruments. In addition, the Reciproc and NIC instruments produced similar root canal transportation for the preparation of mesial canals of mandibular molars. Further investigations should be conducted for comparison of Reciproc and NIC reciprocating instruments in debris removal or formation of dentinal cracks.

\section{Conclusion}

Within the limitations of this study, the NIC instruments have similar cyclic fatigue values to Reciproc instruments. The root canal transportation and centering ration of the NIC were similar to that produced with the Reciproc.

\section{Acknowledgements}

The authors deny any conflicts of interest related to this study.

\section{Conflict of interest: None declared.}

\section{References}

1. Sattapan B, Nervo GJ, Palamara JE, Messer HH. Defects in rotary nickel-titanium files after clinical use. J Endod 2000;26:161-5. [CrossRef]

2. Berutti E, Chiandussi G, Paolino DS, Scotti N, Cantatore G, Castellucci A, et al. Canal shaping with WaveOne Primary reciprocating files and ProTaper system: a comparative study. J Endod 2012;38:505-9. [CrossRef]

3. Peters OA, Barbakow F. Dynamic torque and apical forces of ProFile.04 rotary instruments during preparation of curved canals. Int Endod J 2002;35:379-89. [CrossRef]

4. Roane JB, Sabala CL, Duncanson MG Jr. The "balanced force" concept for instrumentation of curved canals. J Endod 1985;11:203-11. [CrossRef]

5. Weine FS, Kelly RF, Bray KE. Effect of preparation with endodontic handpieces on original canal shape. J Endod 1976;2:298-303. [CrossRef]

6. Gergi R, Rjeily JA, Sader J, Naaman A. Comparison of canal transportation and centering ability of twisted files, Pathfile-ProTaper system, and stainless steel hand K-files by using computed tomography. J Endod 2010;36:904-7.

7. Short JA, Morgan LA, Baumgartner JC. A comparison of canal centering ability of four instrumentation techniques. J Endod 1997;23:503-7. [CrossRef]

8. Plotino G, Grande NM, Testarelli L, Gambarini G. Cyclic fatigue of Reciproc and WaveOne reciprocating instruments. Int Endod J 2012;45:614-8. [CrossRef]

9. De-Deus G, Moreira EJ, Lopes HP, Elias CN. Extended cyclic fatigue life of F2 ProTaper instruments used in reciprocating movement. Int Endod J 2010;43:1063-8.

10. Kiefner P, Ban M, De-Deus G. Is the reciprocating movement per se able to improve the cyclic fatigue resistance of instruments? Int Endod J 2014;47:430-6. [CrossRef]

11. Larsen CM, Watanabe I, Glickman GN, He J. Cyclic fatigue analysis of a new generation of nickel titanium rotary instruments. J Endod 2009;35:401-3. [CrossRef]

12. Gambill JM, Alder M, del Rio CE. Comparison of nickeltitanium and stainless steel hand-file instrumentation using computed tomography. J Endod 1996;22:369-75.

13. Elnaghy AM, Elsaka SE. Evaluation of root canal transportation, centering ratio, and remaining dentin thickness associated with ProTaper Next instruments with and without glide path. J Endod 2014;40:2053-6. [CrossRef]

14. Hashem AA, Ghoneim AG, Lutfy RA, Foda MY, Omar GA. Geometric analysis of root canals prepared by four rotary NiTi shaping systems. J Endod 2012;38:996-1000.

15. Hartmann MS, Barletta FB, Camargo Fontanella VR, Vanni JR. Canal transportation after root canal instrumentation: a comparative study with computed tomography. J Endod 2007;33:962-5. [CrossRef]

16. Zinelis S, Darabara M, Takase T, Ogane K, Papadimitriou GD. The effect of thermal treatment on the resistance of nickel-titanium rotary files in cyclic fatigue. Oral Surg Oral Med Oral Pathol Oral Radiol Endod 2007;103:843-7.

17. Bouska J, Justman B, Williamson A, DeLong C, Qian F. Resistance to cyclic fatigue failure of a new endodontic rotary file. J Endod 2012;38:667-9. [CrossRef]

18. Pedullà E, Grande NM, Plotino G, Palermo F, Gambarini G, Rapisarda E. Cyclic fatigue resistance of two reciprocating nickel-titanium instruments after immersion in sodium hypochlorite. Int Endod J 2013;46:155-9. [CrossRef]

19. Capar ID, Kaval ME, Ertas H, Sen BH. Comparison of the cyclic fatigue resistance of 5 different rotary pathfinding instruments made of conventional nickel-titanium wire, $\mathrm{M}$ wire, and controlled memory wire. J Endod 2015;41:535-8.

20. Plotino G, Grande NM, Cordaro M, Testarelli L, Gambarini $\mathrm{G}$. A review of cyclic fatigue testing of nickel-titanium rotary instruments. J Endod 2009;35:1469-76. [CrossRef] 